\title{
ROBÓTICA, CINE Y DERECHO ${ }^{1}$
}

\author{
ANA LAMBEA RUEDA \\ PDI Laboral del Departamento de Derecho Civil \\ Universidad Complutense de Madrid \\ alambear@ucm.es
}

RESUMEN: La robótica, en particular la que tiene figura humana -androide- se muestra como un ámbito de desarrollo presente y futuro. Desde la Unión Europea se estudia la futura regulación de las cuestiones éticas y jurídicas que inciden en la robótica en su relación con el ser humano. Se pretende una regulación que persiga la protección de todas las personas que interactúen con robots. El estudio de la evolución de la imagen del robot es mucho más antiguo que su regulación, y está presente en prácticamente todas las disciplinas artísticas. En la cinematografía, en particular, la robótica es una temática recurrente dentro del ámbito de la ciencia ficción. En el artículo se presenta un estudio de la imagen y categoría ética del robot cinematográfico desde los orígenes del cine; analizando su visión desde el ser humano. En dicha evolución se observa el gran peso de la imagen androide, que genera respeto, miedo, incertidumbre; frente a los robots máquinas. Tras el estudio de la evolución de la imagen del robot resulta posible enfrentar con mayor claridad los retos jurídicos que se afrontan. La imagen del robot es fundamental; y más aún en los colectivos necesitados de una protección especial. Ello puede llevar a concluir la necesidad de controlar la imagen del robot y su semejanza con el ser humano en los supuestos de interacción con sujetos necesitados de protección, que no distingan fácilmente realidad de ficción, por razón de edad o de limitaciones físicas temporales o permanentes.

PALABRAS CLAVE: robótica, inteligencia artificial, arte, cine, derecho, imagen.

ABSTRACT: Robotics, in particular that which has a human figure -android- is shown as a sphere of present and future development. The European Union studies the future regulation of ethical and legal issues that affect robotics in its relationship with human beings. The aim is to regulate the protection of all people who interact with robots. The study of the evolution of the image of the robot is much older than its regulation, and is present in virtually all artistic disciplines. In cinematography, in particular, robotics is a recurring theme within the field of science fiction. The article presents a study of the image and ethical category of the cinematographic robot from the origins of cinema; Analyzing his vision from the human being. In this evolution the great weight of the android image is observed, which generates respect, fear, uncertainty; in front of the robots machines. After studying the evolution of the robot's image, it is possible to face with greater clarity the legal challenges that are faced. The image of the robot is fundamental; and even more so in groups in need of special protection. This may lead to the conclusion of the need to control the image of the robot and its resemblance to the human being in the cases of interaction with subjects in need of protection, who do not easily distinguish reality from fiction, due to age or temporary or permanent physical limitations.

KEYWORDS: robotics, artificial intelligence, art, cinema, law, image.

SUMARIO: I. Introducción. II. Personalidad electrónica. III. Robots y ARTE. IV. Robots y Cine: CINEMATOGRAFía ROBÓtICA. V. LA IMAGEN DEL ROBOT EN LA CINEMATOGRAFía DE LOS SIGLOS XX Y XXI. VI. CONSECUENCIAS JURÍDICAS DE LA IMAGEN DEL ROBOT. VII. A MODO DE CONCLUSIÓN: ROBOT, IMAGEN Y DERECHO, MÁS CERCA DE LO QUE PUEDE PARECER. VIII. BIBLIOGRAFÍA.

\footnotetext{
${ }^{1}$ Trabajo en el marco del Proyecto CERTIFICARSE (DE 2015-65374-R) Efectos jurídicos financieros y control del impacto social para el desarrollo sostenible; y en el marco del Proyecto INBOTS.EU www.inbots.eu
} 


\section{INTRODUCCIÓN}

Nos encontramos inmersos en una revolución tecnológica imprevisible, llamada cuarta revolución industrial ${ }^{2}$; el desarrollo exponencial de la robótica y la inteligencia artificial es cada vez mayor, colaborando o incluso sustituyendo en algunos ámbitos al ser humano ${ }^{3}$.

En las últimas décadas, e incluso siglos, se ha manifestado de forma recurrente el interés del ser humano en desarrollar máquinas e ingenios a su imagen y semejanza. Ello responde a un interés de creación como si de un ser omnipotente se tratara, bien a través de la autorrepresentación o de otras formas. El robot, como otros tantos engendros mecánicos, creación del hombre, llega a ser una forma de "conocer, dominar y conjurar su naturaleza y el mundo"4.

\section{PERSONALIDAD ELECTRÓNICA}

La robótica, en particular la que tiene figura humana -androide-, es un ámbito de desarrollo presente y futuro. Desde la Unión Europea se estudia la futura regulación de las cuestiones éticas y jurídicas que inciden en la robótica en su relación con el ser humano. Se pretende una regulación que persiga la protección de todas las personas que interactúen con robots.

Desde el punto de vista jurídico, en los últimos tiempos, se ha planteado incluso el intento de la consideración de la personalidad electrónica para los robots con forma humana; tendencia que va siendo abandonada por la consideración del ser humano como único e irrepetible, y los problemas éticos, de responsabilidad y los riesgos que conlleva. Se observa que la identificación física con el ser humano, la imagen del robot androide, su representación, contribuye a esta tendencia.

En 2017, la Resolución del Parlamento Europeo ${ }^{5}$, propuso que se explorara y analizara "crear a largo plazo una personalidad jurídica específica para los robots...". Así, el Parlamento Europeo entendía que podría partirse de las características de un robot inteligente, y regular los problemas de responsabilidad de éste, olvidándose de otras opciones como la creación de seguros obligatorios, fondos de compensación, régimen de responsabilidad específico, o un registro de robots; optando por una personalidad jurídica robótica específica.

Alguna doctrina se manifiesta a favor de esta opción ${ }^{6}$; aunque realmente el

\footnotetext{
${ }^{2}$ ANGUIANO, J.M (2018): "Las personas electrónicas". Diario la Ley, núm. 14, sección Ciberderecho, 18 de enero de 2018. Disponible en http://diariolaley.laley.es/home/DT0000263132/20180118/Las-personas-electronicas, fecha de consulta enero de 2018.

${ }^{3}$ SÁNCHEZ-URÁN AZAÑA, Y GRAU RUIZ, A: “Inteligencia Artificial (definida como el conjunto de tecnologías dedicadas a replicar en máquinas procesos cognitivos parecidos a los humanos) NO CONFUNDIR con la Robótica (Robots con o sin IA)": en PONENCIA: El impacto de la robótica, en especial, la robótica inclusiva en el trabajo: aspectos jurídico laborales y fiscales, Congreso Internacional Technological innovation and the future of work: emerging aspects worldwide, Santiago de Compostela 4-5 abril 2018.

${ }^{4}$ CREGO, C (2007): La muñeca el maniquí y el robot en el arte del siglo xx: perversa y utópica. Editorial Arada, Madrid 2007, pp. 5.

5 P8_TA (2017) 0051; Comisión de Asuntos Jurídicos PE 582.443 Resolución del Parlamento Europeo, de 16 de febrero de 2017, con recomendaciones destinadas a la Comisión sobre normas de Derecho civil sobre robótica (2015/2103(INL)).

${ }^{6}$ BARRIO ANDRÉS, M (2018): «Hacia una personalidad electrónica para los robots», op.cit, pp. 97.
} 
responsabilidad de los sujetos intervinientes en la fabricación y puesta en funcionamiento del robot, se opta por la personalidad y, en consecuencia, responsabilidad del robot por lo actuado. Sin embargo, son muchos más los que no opinamos asî ${ }^{7}$. En mi modesta opinión, totalmente de acuerdo en la necesidad de concretar responsabilidades - cajas negras, seguro obligatorio, y/o de Registro de Robots-; aunque ello no puede condicionar la visión de esta nueva realidad.

Además, tampoco es admisible, como dichos autores proponen, considerar al robot como persona electrónica independiente en materia de derechos patrimoniales -titular con deberes y derechos -, y no con relación a los derechos de la personalidad, para no enfrentarse al debate de fondo: si es sujeto u objeto. Y ello pese a que la propia independencia física del robot facilita considerarlo como sujeto.

Tampoco podemos considerar a los robots como seres sensibles. El robot no tiene sentimientos, su realidad es física, intelectual, pero no emocional. Éste ha sido uno de los grandes debates y propuestas desde otras disciplinas, como la artística: ¿tiene el robot sentimientos, empatía, es una máquina o, en parte, humano? Aunque aparentemente el coste de oportunidad pudiera ser favorable a su personalidad electrónico-jurídica independiente, una visión a largo plazo requiere reflexionar acerca del concepto de robot: ¿tipo de robot con el que queremos convivir?; ¿a nuestra imagen y semejanza?, ¿una réplica humana?; por el contrario, ¿es preferible un robot-máquina?, ¿un colaborador del ser humano?, ¿un objeto?; ¿Cuál debería ser la imagen de dicho robot? En mi opinión, es importante elaborar normas innovadoras en el ámbito de la robótica e inteligencia artificial, que garanticen la seguridad jurídica de los ciudadanos.

En el mundo actual, los tipos de robots son diversos tanto por sus especialidades técnicas, como en función del ámbito de trabajo en que se mueven: industrial, asistencial, ocio... También su funcionamiento puede ser determinante, en función de que se trate de robots con o sin interrelación directa con usuarios. Deberían y podrían distinguirse varios tipos de robots 8 : "1. Robot sobre el que el ser humano mantiene el control total y absoluto de sus acciones; 2. Robot sobre el que el ser humano tiene el control necesario para poder parar su funcionamiento en un momento determinado; 3. Robots con objetivo y ejecución propios, sin posibilidad de control por parte del ser humano". En mi opinión, incluso en este caso podrían distinguirse los que pueden ser controlados y los que no. Con relación a sus componentes puede distinguirse entre electromecánicos, microscópicos y de software; mientras que la variedad en función de la actividad es muy amplia: ambiental, cirugía, prótesis, salud, uso profesional, uso militar, educación, juguetes, entretenimiento, arte ${ }^{9}$.

En todo caso, se observa un desarrollo cada vez mayor de la robótica en interrelación con el ser humano, con los consiguientes problemas éticos, de responsabilidad, etc. ${ }^{10}$

\footnotetext{
${ }^{7}$ DÍAZ ALABART, S (2018): Robots y responsabilidad civil. Op.cit, pp. 73 y ss.

${ }^{8}$ MEZA RIVAS, M; ESPÓSITO, C (2017): «Killer robots y sistemas de armas autónomos en el marco del derecho internacional. Implicaciones, desafíos y riesgos», Acta resumen y conclusiones de \#Robot Iuris 2017, 16 de noviembre de 2017, pp. 17-19: «... Así pues, en el binomio humano/máquina hay diferentes grados de control: Human in the loop: El humano tiene el control total y absoluto de las acciones llevadas a cabo. - Human on the loop: El humano tiene el control necesario para poder parar la máquina en un momento determinado. - Human out the loop: El humano no puede parar el objetivo que se ha puesto la máquina.»

${ }^{9}$ GARCÍA PRIETO, J (2018): «¿Qué es un robot?», Op.cit, pp. 42-45.

${ }^{10}$ A juicio de PALMERINI, E (2017): Robótica y derecho: sugerencias, confluencias, evoluciones en el marco de una investigación europea. Op.cit, pág. 63 y ss.: La autora propone diversos esquemas alternativos: 1. La limitación de la responsabilidad, que permite, por un lado, promover la innovación en la investigación y en la industria robótica; por el otro, 1 garantizar inmunidad a los fabricantes frente a eventos dañosos que no habrían podido ser evitados usando la debida diligencia, al diseñar el producto y al informar al consumidor de sus riesgos potenciales. Como una
} 


\section{ROBOTS Y ARTE}

El estudio de la evolución de la imagen del robot es mucho más antiguo que su regulación. Podríamos afirmar que la robótica está presente en nuestra civilización desde hace siglos. Incluso, desde la Grecia clásica se anunciaban hombres o Dioses que podían traer a la vida a criaturas mecanizadas o no -en la literatura, la mitología, de uno u otro sexo- ${ }^{11}$. También es una cuestión recurrente desde el ámbito científico, incluso en la época de la Escuela de Alejandría -Herón y su tratado: autómatas- el Imperio Romano, la Edad Media -científicos y estudiosos, filósofos... como Leonardo da Vinci, Descartes-. Y fundamentalmente en la etapa contemporánea, en los últimos dos siglos XIX y XX desde diversos ámbitos científicos y artísticos.

La relación entre los robots y el arte tiene varias facetas de desarrollo interesantes. Puede destacarse, desde la perspectiva artística, que el desarrollo de la maquinaria robótica y de la inteligencia artificial (IA) con figura humana, ha oscilado entre tener en cuenta la imagen y representación del ser humano como base, adaptándola a la realidad técnica, o alejarse de ella. Es interesante observar la evolución de la robótica y los engendros con forma humana en los últimos dos siglos, ya que realmente la automatización del siglo XIX es el antecedente de la robótica actual. Al hablar de robots hay varias imágenes de éstos ${ }^{12}$ : la imagen del humanoide metálico geométrico que se mueve y emite breves frases; la imagen del robot industrial aparatoso y voluminoso; el robot androide que se confunde con el ser humano; y también los cyborgs como seres humanos cargados de prótesis, estimuladores, microprocesadores...

El origen del término robot lo encontramos en Praga en 1921, en "Rossum' s universal robots". Karel Capek recurre a esta palabra para referirse al trabajador esclavo o forzado, criaturas humanoides que evitaban trabajo a los seres humanos, y finalmente se rebelan con el fin de destruir la humanidad. Posteriormente, Isaac Asimov recoge este término en sus obras de ciencia ficción, e inventa las tres leyes de la robótica en "Yo Robot".

La literatura presenta una evolución característica, oscilando entre los engendros monstruosos derivados del ser humano, o los robots con o sin figura humana. Todos ellos, además, con un comportamiento dual, que oscila entre la ética buena y mala. Por un lado, el engendro con comportamiento excelente, valores éticos, colaborando con el ser humano; y por otro, la máquina o engendro inicialmente colaborador que se convierte en un monstruo destructivo contraviniendo todas las normas de la ética moral y jurídica ${ }^{13}$. Desde la consideración de Descartes, del ser humano como máquina (identificado posteriormente con bombas, relojes... y otras maquinarias de precisión), retomado por La Mettrie en un

\footnotetext{
"inmunidad selectiva"; 2. crear una personalidad jurídica para los robots a los fines de convertirlos directamente en responsables de los eventuales daños causados a terceros (capacidad a los efectos de responsabilidad, identificación, registro); 3. Incremento de la responsabilidad del propietario de la máquina frente a la tutela del eventual perjudicado, con base en un criterio de responsabilidad objetiva con un límite máximo de resarcimiento.

Sobre el tema de responsabilidad civil de la robótica, presenta las diversas opciones actuales, estudiando según la normativa actual -productos defectuosos- y ofreciendo una interpretación de la misma, así como esbozando un esquema posible respecto de las normas futuras respecto de: quien reclama, causas de reclamación y posibles exenciones, determinación de los responsables y ejercicio de la acción: DÍAZ ALABART, S (2018): Robots y responsabilidad civil. Reus, Madrid 2018, pág. 101 y ss.

${ }^{11}$ IGLESIAS GARCÍA, R (2016): Arte y robótica. Casimiro, Madrid 2016, pp. 18 y ss. Cita la Ilíada, la mitología...

${ }^{12}$ PERA, C (2006): Pensar desde el cuerpo; ensayo sobre la corporeidad humana. Ed. Triacastela, Madrid, pp. $230 \mathrm{y}$ SS.

${ }^{13}$ CREGO, C (2007): La muñeca el maniquí y el robot en el arte del siglo XX: perversa y utópica. Editorial Arada, Madrid 2007, presenta un resumen de dicha evolución en lo artístico en las pp. 7 y ss.
} 
materialismo maquinista en "El hombre máquina" en 1747 opuesto al dualismo de Descartes, "El hombre planta" en 1748 -también Jean Paul, Bonaventura-. La literatura va evolucionando en relatos sobre seres y autómatas creados de forma más o menos compleja en el siglo XVIII Vaucanson, Droz, Von Kempelen, Edgar Allan Poe, Hoffman, Villiers de 1'Isle- con referencia al término autómata -movimiento por sí mismo- y androide -con figura humana-. Se refleja en la literatura la gran preocupación por el devenir de dichos engendros y máquinas y su relación con el ser humano -hay también algunos críticos que argumentan en contra de la mecanización y automatización como Butler-. Dichos relatos dejan paso en el siglo XIX a otros seres amenazantes y/o monstruosos como Olimpia de Hoffman o Frankenstein de Shelley. En el ámbito de la medicina también destacan los estudios que explican el funcionamiento de nuestro cuerpo de forma mecánica o similar a las máquinas, como así ocurre en La vida del hombre de Fritz Kahn, en 1922-1931.

En la pintura antecedente al desarrollo de los robots de los últimos 50 años, también se observa, con origen seguramente en el siglo XIX, una evolución interesante. En el siglo XIX figuras semejantes a la humana, de escaso contenido, como es el caso del pelele de Goya en 1791 y otros posteriores; representando seres inanimados; que posteriormente dejan paso a seres animados. Ya en el siglo XX se observa una desestructuración de la figura humana, y surgen figuras articuladas mecánicamente ${ }^{14}$, como reflejo de una realidad social rota y desestructurada por las guerras, especialmente en la primera mitad del siglo. Esa desestructuración se observa también en otros ámbitos de lo artístico, incluso como fuerza contraria de creación de figuras mecánicas robóticas semejantes al ser humano en la cinematografía. Por otra parte, paralelamente surgen corrientes artísticas que presentan, o bien un acercamiento a lo figurativo con una visión absolutamente diferente a la tradicional -surrealismo, neo figuración, pop-art, hiperrealismo-; o una ruptura absoluta con la figuración. En la actualidad, el arte robótico está aquí, inmerso o no en el transhumanismo, que pretende defender y replantear la condición del ser humano ante la recepción de la tecnología; incluso pensando que la máquina perfecta pudiera sustituir al cuerpo (ciborg). Y a la vez, en contraposición a lo anterior, surgen desarrollos pictóricos de artistas que presentan a la persona inmersa en una sociedad capitalista como ser atrapado en una máquina, como es el caso de Tetsuya Ishida.

La representación autónoma de la figura humana, o la figura humana, a través de la escultura, se observa desde el inicio de los tiempos. Incluso en etapas inciertas de la Prehistoria -Venus-, o en las estatuas del Antiguo Egipto, y de la Grecia clásica. Más adelante, por ejemplo, bajo la apariencia de divinidades y animales en el arte íbero y fenicio de los pueblos mediterráneos antiguos, incorporados en algunos conjuntos arquitectónicos al arte cristiano románico. Pero es en el siglo XX cuando se produce una gran revolución en la escultura, abandonando tanto las figuras humana y animal, la armonía, el realismo, y dejando paso a la geometría -abstracción geométrica-, el dramatismo y las formas inventadas, más o menos lineales o difusas y retorcidas; con una profusión cada vez mayor de materiales -reflejo en el cubismo, el expresionismo-.

\footnotetext{
${ }^{14}$ CREGO, C (2007): La muñeca el maniquí y el robot en el arte del siglo XX: perversa y utópica. Editorial Arada, Madrid 2007, pp. 31 y ss., cita a De Chirico, Morandi, George Grosz, Hausmann, Hans Bellmer, Picabia, Duchamp, Kokoschka, Sherman, Chapman, Schlemmer. También estudia el fenómeno en la construcción de figuras, y presenta esa misma evolución, especialmente en la etapa del pop art: Ron Mueck, De Andrea, Allan Jones, Charles Ray, Robert Graham, George Segal y Duane Hanson. IGLESIAS GARCÍA, R (2016): Arte y robótica. Casimiro, Madrid 2016, pp. 150 y ss. Cita a Schöffer, pionero en el arte del movimiento y el uso de técnicas electrónicas, cibernéticas e industriales.
} 
En la actualidad se abre paso la tendencia de considerar la tecnología como un ámbito de experimentación estética que da lugar al arte robótico ${ }^{15}$. Se habla del mismo como una nueva forma de arte, creado de forma similar al arte conceptual ${ }^{16}$. El arte robótico se considera relacional, y lleva a la participación física, psíquica o social del ser humano en dicho arte ${ }^{17}$. Para estos autores, la tecnología se convierte en arte robótico si desde el punto de vista subjetivo u objetivo logra expresar el creador y si conecta con una respuesta del espectador ${ }^{18}$.

Por otro lado, incluso en algún caso, se ha cuestionado si la creación del robot, como figura semejante al ser humano, podría ser considerada una creación escultórica y como arte en movimiento, dentro del arte kinético ${ }^{19}$, incluso como arte robótico.
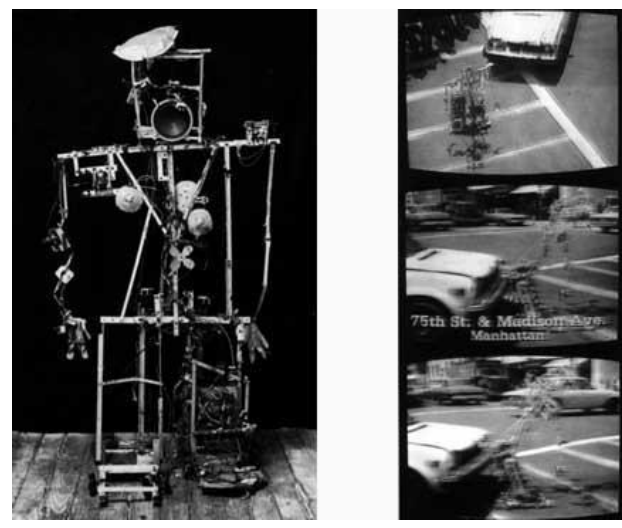

ROBOT K-456

\footnotetext{
${ }^{15}$ IGLESIAS GARCÍA, R (2016): Arte y robótica. Casimiro, Madrid 2016, pp. 105 y ss. Cita a Eduardo Kac, uno de los artistas que más ha desarrollado y aplicado la tecnología al arte -planteando muestras de ciborg -hombre y robot-; y a Marcel Antúnez Roca como autor del Manifiesto robótico -octubre 1996-, en que indica los conceptos principales sobre los que se asienta el arte robótico, sobre la base de los art robots como nueva forma de arte. Se afirma que los robots no son esculturas, pinturas o video; son objetos, estructuras, agentes, que nacen en espacios físicos, telemáticos, entornos virtuales o una combinación de todos ellos; son algo nuevo en el mundo del arte, cuyo desarrollo se produce en un nuevo territorio. Este manifiesto, en línea con otros citados por el autor como el Manifiesto del macchinismo, 1952, de Bruno Munari, reivindicando el arte de las máquinas. También cita, como exponentes del ARTE ROBÓTICO, en la línea de performances en el ámbito tecnológico, a Roberta Breitmore y sus copias de mujeres virtuales -pp.227-; a Simon Penny y sus escritos relacionando la tecnología y diversas funciones del cuerpo -pp. 244-; la robótica industrial -Robolab- y sanitaria -pp. 284-; Carlos Corpa y sus formatos de reciclado; France Cadet y sus instalaciones críticas, y animales robóticos transformados a imagen de la modificación genética pp. 288-; Fernando Orellana, sus robots humanoides, y sus ocupantes del ascensor -pp. 295-. Sin embargo, IGLESIAS GARCÍA advierte de que el arte robótico persigue una perfección mecánica, sin emoción ni diálogo; aunque puede lograr convertirse en robótica social -como los Relational artefacts, Messaris 2006, los Tamagotchi y otros...- incluso lograr la creación de seres artificiales semejantes al ser humano -Cog creado por Rodney Brooks en el MIT, pp. 299; o KIsmet, primer robot emocional funcionando con algoritmos de aprendizaje de la emoción humana-.

${ }^{16}$ Del que se dice que es "hermano": IGLESIAS GARCÍA, R (2016): Arte y robótica. Casimiro, Madrid 2016, pp. 146.

${ }^{17}$ Como afirma IGLESIAS GARCÍA, R (2016): Arte y robótica. Casimiro, Madrid 2016, pp. 327.

${ }^{18}$ IGLESIAS GARCÍA, R (2016): Arte y robótica. Casimiro, Madrid 2016, pp. 331: Nuevas formas de arte robótico o electrónico se encuentran en el arte electrónico, media art, ciberarte, net.art, software.art, bioarte... Iglesias afirma (citando a Rokeby 1995) que "la tarea del artista consiste en explorar y al mismo tiempo cuestionar, retar y transformar las tecnologías que usa".

${ }^{19}$ Una posición más radical sería sostener que la investigación en robótica es intrínsecamente arte. En "Beyond Modern Sculpture" el teórico del arte Jack Burnham sugiere que la auto-replicación fue el núcleo del arte y que la robótica fue una continuación inevitable de esa búsqueda. Estas ideas son interesantes para algunos artistas que trabajan en el campo. Sobre las bases de las ideas de Burnham, Bruce Cannon, escribió un ensayo titulado "Art in the Age of the Microcontroller", el cual considera la estética inherente de la electrónica y la robótica: https://hacedores.com/robotica-en-el-arte-y-arte-kinetico/. WILSON, Stephen. Information arts. Intersections of art, science, and technology. The MIT Press, Massachusetts, 2002, Nam June Paik y Shya Abe crearon el robot K-456 en 1964.
} 
En la actualidad, también se cuestiona la creación artística de robots $\operatorname{artistas}^{20}$, creaciones fruto del trabajo algorítmico, si bien todavía como herramientas al servicio del ser humano. Así pues, el ganador del concurso de RobotArt 2018 fue Cloud Painter. Sin embargo, en este caso, las creaciones robóticas no se asemejan al ser humano en el aspecto físico, en su imagen, y sí en el creativo.

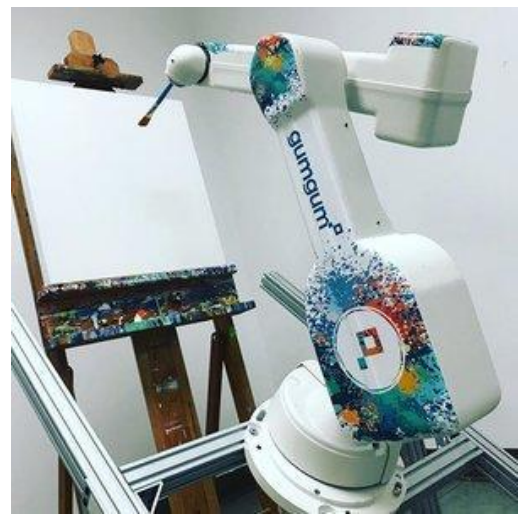

El debate acerca de la creación artística mediante la robótica y sus resultados se encuentra abierto: "Hace apenas unos meses la casa Christie's realizó la primera subasta de arte creado por Inteligencia Artificial. ¿El resultado? Unas ventas de 432.500 dólares” ${ }^{\text {} 21}$.

\section{ROBOTS Y CINE: CINEMATOGRAFÍA ROBÓTICA}

En la cinematografía, en particular, la robótica es una temática recurrente dentro del ámbito de la ciencia ficción. En este artículo se presenta un estudio de la imagen y categoría ética del robot cinematográfico desde los orígenes del cine; analizando su visión desde el ser humano. En dicha evolución se observa el gran peso de la imagen androide, que genera respeto, miedo, incertidumbre; frente a los robots máquinas.

Desde el origen del cine, incluso y en el cine mudo, se observan multitud de desarrollo de robots. Podríamos hablar de una cinematografía robótica, ya que la cinematografía encontró un campo de desarrollo extraordinario en la robótica, dentro del género de la ciencia ficción.

Inicialmente los robots eran creaciones artesanales ${ }^{22}$, a diferencia de la actualidad. Ello supone una evolución importante desde el punto de vista de su creación, llegando al uso de nuevas tecnologías informáticas.

En el estudio de la filmografía robótica se observa una evolución del robot, semejante al ser humano o no, según las épocas. La representación del robot se presenta como un humanoide o androide, o incluso exactamente igual que el ser humano, confundiéndose con él, o bien con aspecto bien diferenciado, materiales metálicos, sin rasgos humanos... En la actualidad, en la década de los 2010-2019, el robot que se presenta es una máquina de dimensiones extraordinarias. Quizá porque en las décadas anteriores los robots androides guardaban tanta

\footnotetext{
20 https://www.nobbot.com/arte/robots-artistas-robotart/; https://www.xataka.com/robotica-e-ia/esta-obra-arte-fuepintada-robot-ganadora-concurso-robotart-2018 .

${ }^{21}$ https://www.iberdrola.com/te-interesa/cultura/arte-computacional-robots-artistas

${ }^{22}$ Aunque el antecedente más remoto de la robótica podríamos encontrarlo en la animatrónica (Japón): siglos antes de Cristo existían muñecas móviles mediante cuerdas incorporadas en su interior: https://robotsaldetalle.es/noticias/historia-de-los-robots-en-el-cine/
} 
semejanza con el ser humano... que se confundían con él, generando inquietud. Esta inquietud y miedo, que depende en esencia de la imagen del robot, puede influir en el desarrollo de la robótica como herramienta al servicio del ser humano. En mi opinión, la imagen puede influir más aún en el caso de los colectivos necesitados de una atención especial, como es el caso de menores de edad o personas con alguna limitación o restricción de capacidad y entendimiento.

Por otra parte, en el ámbito de la ética y del aspecto jurídico de los derechos, la perspectiva cinematográfica de la robótica oscila también entre dos polos opuestos: el robot como monstruo engendrado para el mal y el robot como expresión del defensor de todos los ideales y valores del ser humano.

Hasta la década de los años 20 del siglo XX, dentro del cine mudo, encontramos la primera película de ciencia ficción, Viaje a la Luna en 1902 -en ella aparecen los selenitas, pero no son robots-. En 1906, se presenta Motor Vallet de Arthur Cooper, y en 1910 el primer robot femenino: Mechanichal Mary Anne. El cine mudo trata también en ocasiones la mecanización del trabajo, no con la imagen de robots o androides independientes, sino con una herramienta de apoyo al ser humano, como ocurre por ejemplo en Tiempos modernos.

Tendremos que esperar a la década de los años 30 en que surgen las primeras aportaciones de filmografía realmente robótica. A partir de aquí, como he advertido, se van presentando tanto figuras con materiales metálicos de formas diversas o asemejando la figura humana, como androides o robots semejantes al ser humano que se confunden con él.

La primera película del cine que presenta un personaje robótico (Maria II) es Metrópolis en 1927, dirigida por Fritz Lang, dentro del expresionismo alemán. En este caso, el robot suplanta al ser humano y lanza discursos incendiarios entre los trabajadores, y además ejecuta un plan de venganza, promoviendo la discordia y la decadencia entre los jóvenes. Siguiendo al robot, los trabajadores inician una revuelta y destruyen la máquina que proporciona energía a la ciudad. Los tanques de agua de la ciudad se inundan, e inundan el mundo de los trabajadores que no se han ocupado de su seguridad y la de su familia. Los trabajadores, conocedores de su error, van en busca del robot impostor -al que prenden fuego, quedando al descubierto que era un robot -su apariencia era humana, pero el interior era metálico- y no un ser humano suplantado, y llegando a la reconciliación de los trabajadores y su empleador. En este caso, la imagen del robot es humana -en su interior no-, y se confunde con el ser humano, y su actitud y ética son rechazables, perseguidos y castigados.

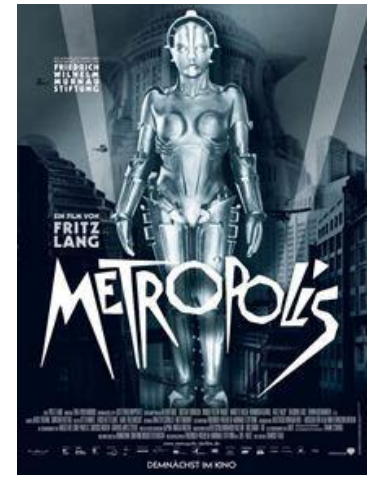

En los años 50, en el entorno de la Guerra Fría, aparece Gort, un robot de hojalata, sin apariencia humana, en El día que paralizaron la Tierra, película americana de ciencia ficción dirigida por Robert Wise. Gort es un extraterrestre que ha venido a la Tierra para impedir las armas nucleares post-bomba atómica. Ello sería una amenaza para el resto de los planetas habitados, que en consecuencia destruirían la Tierra. El robot suspende temporalmente 
la electricidad de la tierra, y es perseguido. Finalmente abandona la tierra, aunque deja su mensaje de prevención, que cobra un sentido pleno teniendo en cuenta el desarrollo de la energía y las armas nucleares y sus consecuencias en la segunda guerra mundial. En el caso de Gort, la imagen del robot es metálica, y su compromiso ético del robot es positivo.

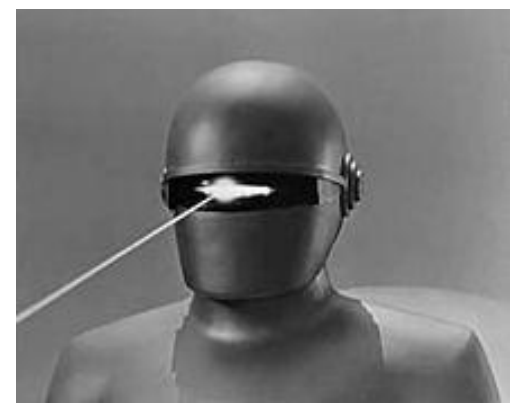

Dentro del manga (cómic en Japón) surge en 1951 ASTROBOY, creado por Osamu Tezuka. La historia sigue las aventuras de un androide llamado Astro Boy. Es una historia de ciencia ficción en un mundo futurista donde los robots coexisten con los humanos. Trata de un androide creado para reemplazar a un hijo fallecido, incorporando las memorias de éste. Sin embargo, su creador lo rechaza al ver que no puede crecer ni expresar emociones. El androide es acogido por un nuevo padre, que se da cuenta de que Astro tiene poderes y habilidades superiores, y la capacidad de experimentar las emociones humanas. Astro comienza a luchar contra el crimen, el mal y la injusticia utilizando sus diversos poderes. La mayoría de sus enemigos son seres humanos que odian los robots, robots que se han vuelto locos o invasores alienígenas. La imagen de Astro Boy es la normal de un personaje de cómic, aunque se fundamenta en la sustitución del ser humano, y sus valores éticos son positivos y defendibles.

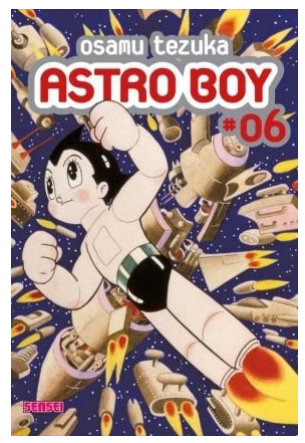

Una década después, en 1968, la famosa 2001 Una odisea del espacio, película de ciencia ficción dirigida por Stanley Kubrick. En ella encontramos a HAL 9000, súper computadora que domina su entorno, y desarrollará comportamientos típicamente humanos, que provocan catastróficos resultados. HAL 9000 es un ordenador perfecto, sin fallos. Es un cerebro artificial educado como un niño. No se sabe si HAL 9000 tiene sentimientos, aunque siente orgullo de sus propias capacidades, y tiene un objetivo único que le obsesiona: lograr que la misión tenga éxito. Ante la encrucijada de no saber qué hacer para ello desarrolla un comportamiento neurótico destructivo, asesinando a los astronautas, y siendo finalmente desconectado.

La película aborda temas como: evolución humana, tecnología, inteligencia artificial y vida extraterrestre. Presenta un realismo científico, con revolucionarios efectos especiales, e imágenes surrealistas. Puede observarse que, desde el punto de vista de la imagen, HAL 9000 es una computadora, no un androide ni siquiera un robot, sin embargo, su desarrollo intelectual es cuasi humano. La racionalidad que representa, sin el componente emocional y ético le lleva a 
la neurosis y la destrucción. En mi opinión, presenta con brillantez las consecuencias de desarrollar la mente sin alma ni corazón, una reflexión a tener en cuenta, pensando incluso en el desarrollo del ser humano.

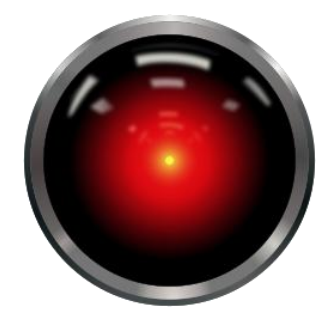

Encontramos otro caso de robots mecánicos, pero con sentimientos humanizados. Los robots 'dronos' que aparecen en Naves misteriosas, película americana de ciencia ficción, dirigida en 1972 por Douglas Trumbull. La vida vegetal ha desaparecido de la tierra, y lo que queda de la flora se encuentra en tres naves espaciales botánicas. Un botánico se responsabiliza del cuidado y mantenimiento de una de ellas; recibe la orden de destruir las especies y regresar a la Tierra. Por ello, huye en la nave, matando a la tripulación. Lo hace en compañía de Huey y Dewey, robots de mantenimiento que reprograma, tratando de defender los recursos naturales que le permiten sobrevivir. Los dronos son robots de apariencia metálica, pero su comportamiento ético es colaborar positivamente con la humanidad.

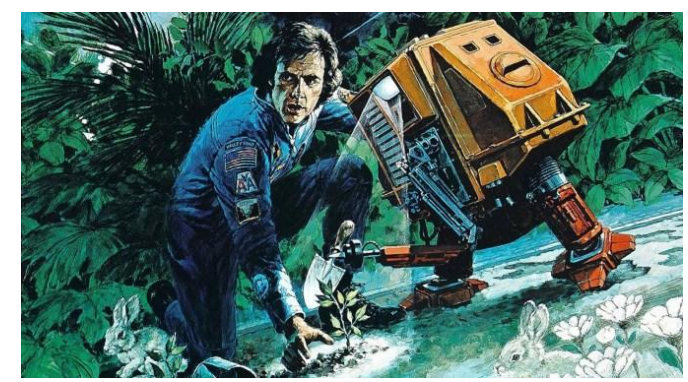

El Mundo del Oeste, película de ciencia ficción escrita y dirigida en USA en 1973 por Michael Crichton, que incorpora por primera vez imágenes de ordenador en varias dimensiones.

La película se sitúa en un parque de atracciones. Los visitantes interactúan con robots humanoides indistinguibles de los humanos, salvo por las manos, programados para aceptar cualquier petición humana, incluidas peticiones sexuales.

Los técnicos del parque advierten problemas con los androides y los encargados del parque deciden cortar el suministro eléctrico, lo que les mantiene atrapados, mientras los robots actúan libres por el parque. En el mundo del oeste tenemos de nuevo androides, con imagen humana, confundiéndose con el ser humano incluso, cuya actuación ética es reprobable, por lo que precisan ser desconectados.

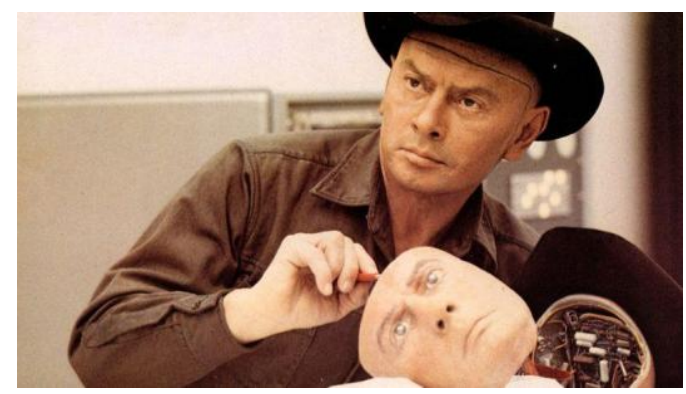


En 1977 se estrenó La guerra de las galaxias, dirigida en USA por George Lucas. Incorpora humanoides de hojalata, como C3PO -con aspecto humanoide- y R2D2, que ayudan a los seres humanos del entorno de la Fuerza -el bien- en la lucha contra el lado oscuro -el mal-.
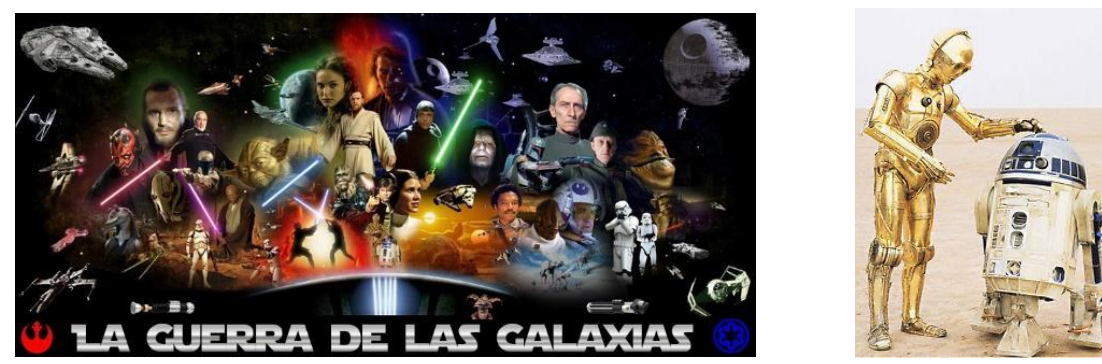

Un año después aparecen los androides, con películas como Android, dirigida en 1978 en EEUU por Aaron Lipstadt. El Dr. Daniel y su ayudante Max, un androide, viven tranquilamente en una estación espacial. Allí trabajan en el próximo proyecto del doctor, la construcción de un androide con forma de mujer. Reciben la visita de tres individuos que huyen de la ley; y uno de ellos es una mujer por la que tanto Daniel como Max sentirán una fuerte atracción. Casualidad o no que ser humano y androide compartan sentimientos de atracción por una mujer, teniendo en cuenta que el androide es similar físicamente al ser humano.

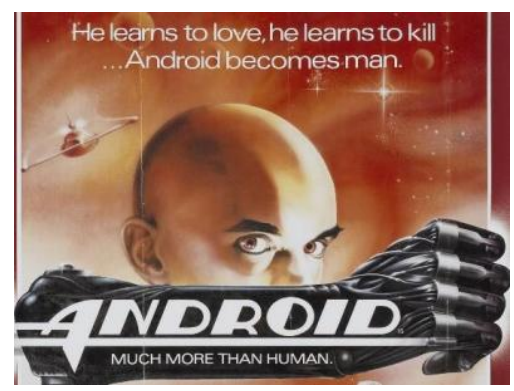

En 1982 se estrena Blade runner, dirigida por Ridley Scott en EEUU. Describe un futuro en que, a partir de ingeniería genética, se fabrican humanos artificiales: los replicantes, para trabajos peligrosos y como esclavos. Los replicantes no se distinguen físicamente de un humano, y tienen más agilidad y fuerza física, aunque no poseen emociones. Los replicantes son declarados ilegales tras un motín; y la policía los busca para matarlos. Los replicantes son androides con figura humana, confundiéndose con el ser humano, sin emociones, pero con mayores capacidades físicas lo que les convierte en una amenaza para el ser humano. De nuevo la ausencia de emociones, y suponemos de alma en un cuerpo físico humano, da como resultado un comportamiento ético destructivo, resultado en parte de la propia actitud del ser humano hacia el androide.
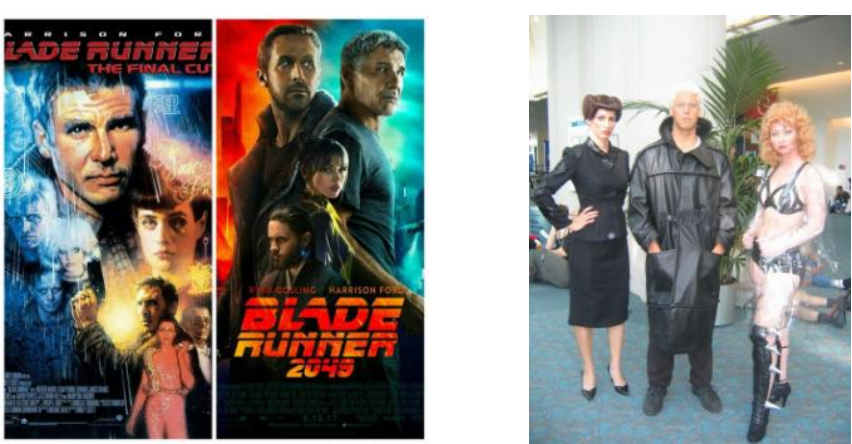
En 1984 se estrena Terminator, el humanoide exterminador, dirigida en USA por James Cameron. Terminator, un ciborg asesino enviado a través del tiempo desde el año 2029 a 1984. En el año 2029, tras devastar la Tierra y esclavizar a la humanidad, las máquinas, gobernadas por la inteligencia artificial, están a punto de perder la guerra contra la resistencia. La estrategia de la IA es eliminar al líder enemigo antes de que este nazca, de modo que no pueda cumplirse su misión. Por ello envía al pasado a un ciborg asesino, con la misión de exterminar a la madre del líder de la resistencia; la resistencia también envía a un soldador para ayudarle. El ciborg lucha y muere. De nuevo, un androide con imagen humana, sobre la base de la inteligencia artificial llevada al extremo de que se vuelve contra la humanidad.

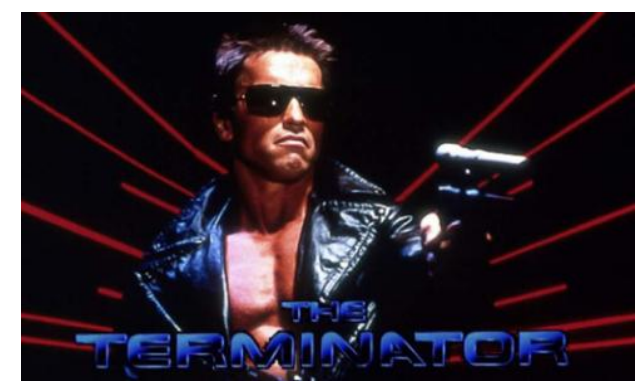

En 1999 se proyecta El hombre bicentenario, cuestionándose las emociones y sentimientos de un robot, e inspirada en la obra de Isaac Asimov y Silverberg -el hombre positrónico-. El robot es adquirido por una familia para realizar todas las tareas importantes de la casa; y se descubre que puede identificar las emociones y la reciprocidad a pesar que ningún robot está diseñado para poseer tales características. Finalmente, tras más de 100 años de vida, contamina su sistema con un compuesto que degradará lentamente su cuerpo, lo que le permitirá envejecer y morir Se le da la bienvenida a la condición humana y comienza a envejecer hasta morir a la edad de 200 años. De nuevo un androide con imagen humana, cuya conducta ética es cuasi humana por el componente emocional, lo que le lleva a ser considerado como ser humano.
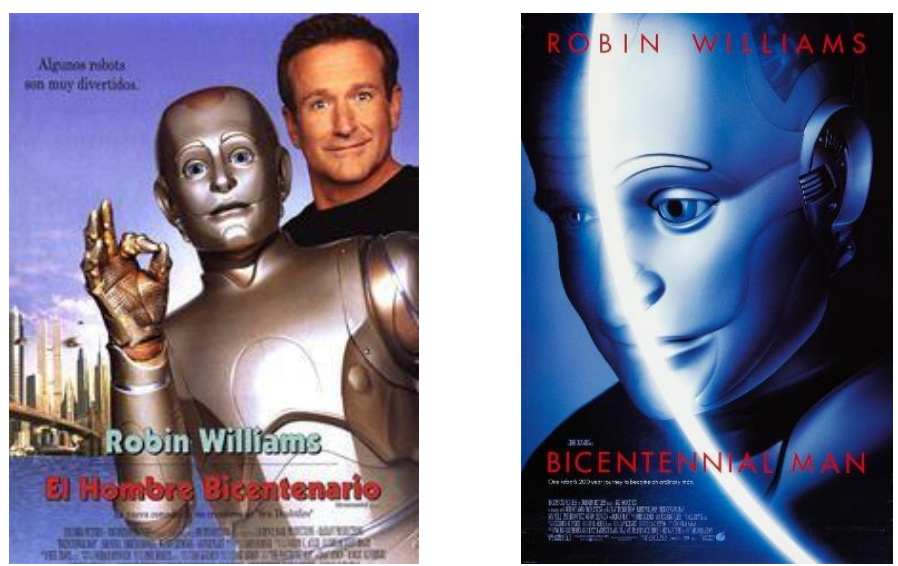

Yo robot, es dirigida en 2004 por Alex Proyas, y basada en la obra de Asimov y en un guión de Jeff Vintar: Hardwired. La acción se desarrolla en 2035 y los robots humanoides forman parte de la vida cotidiana como trabajadores. La compañía dedicada al diseño, construcción y venta de robots tiene previsto el lanzamiento de un nuevo modelo de robot. Se descubre que el ordenador central de la compañía controla a los nuevos robots, y proyecta su rebelión para proteger a la humanidad. Así, como los seres humanos son una raza altamente autodestructiva, el ordenador central crea una ley adicional: "los robots deben proteger a los humanos incluso si tienen que desobedecer la primera y segunda leyes, y matar a algunos de ellos". Finalmente, la supercomputadora se desactiva y los robots recuperan su programación original, volviendo a ser normales, y devolviendo el control a los humanos. Curioso relato de 
ficción, no tanto por la imagen del robot, no humanoide, sino por la reflexión acerca de la ética y el comportamiento del ser humano, y cómo puede volverse en su contra.
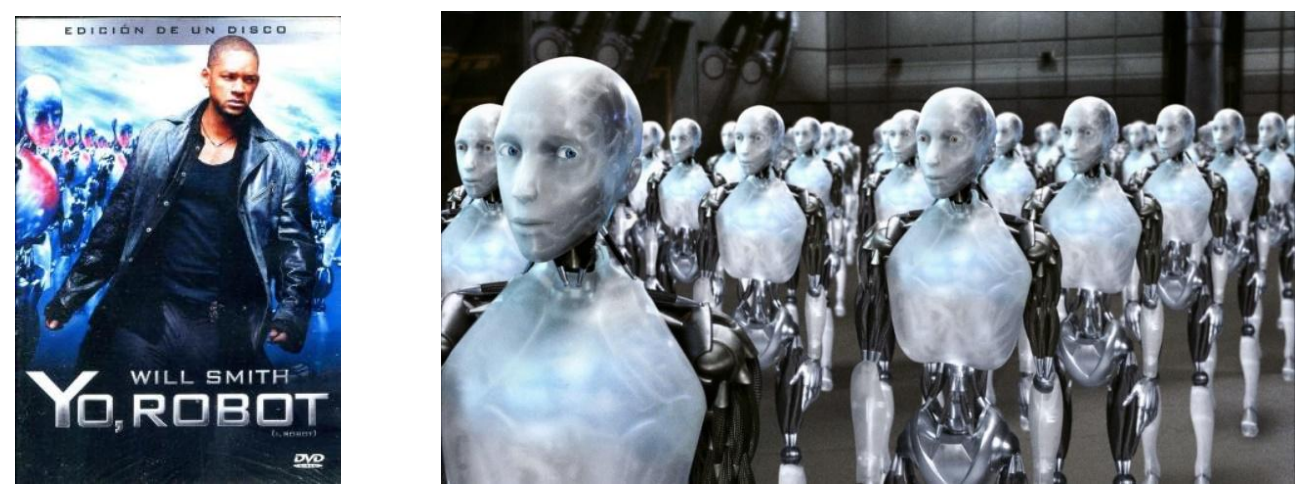

En la última década están de actualidad los grandes robots metálicos. Encontramos, entre otros, en 2007 Transformers, dirigida por Michael Bay. El protagonista queda atrapado en una guerra entre Autobots y Decepticons, que buscan dominar el universo. Se trata de dos tipos de robots que se ocultan en máquinas.

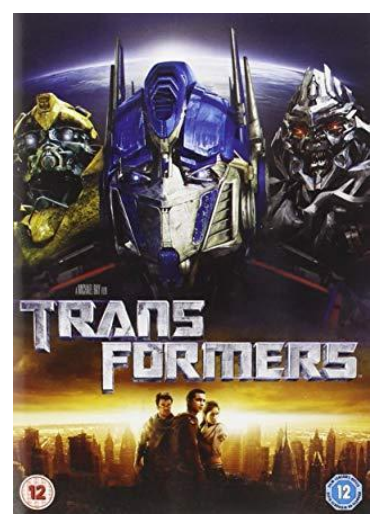

También hay grandes robots en Real Steel dirigida por Shawn Levy en 2011. Ambientada en 2020, los boxeadores humanos son reemplazados por robots, protagonizando varios combates.

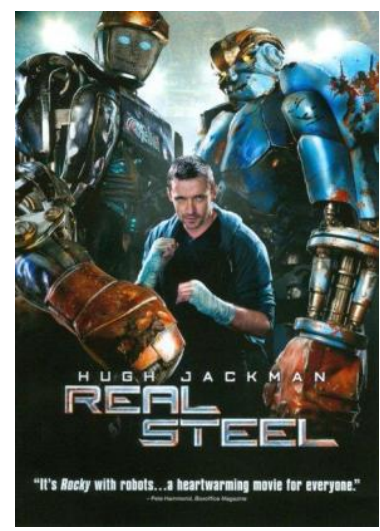

Por último, en 2013 Pacific Rim, dirigida en USA por Guillermo del Toro. La humanidad se enfrenta a monstruos colosales que han surgido a partir de un portal interdimensional en el fondo del Océano Pacífico, "el abismo"; iniciando una guerra que acabará con millones de vida. Para combatirlos se diseña un tipo especial de arma: enormes robots, controlados simultáneamente por dos pilotos, protagonizan la esperanza de la 
humanidad. Una imagen de robots colosales, de aspecto metálico, cuyo comportamiento al servicio del ser humano contribuye a su defensa.

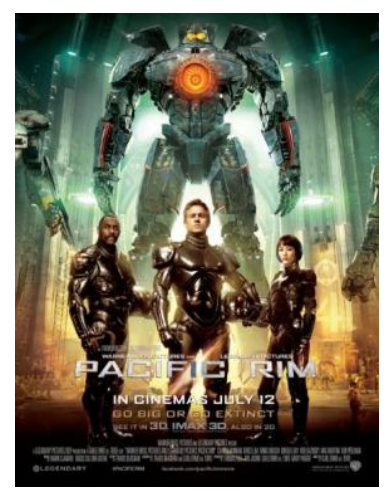

\section{LA IMAGEN DEL ROBOT EN LA CINEMATOGRAFÍA DE LOS S. XX Y XXI}

Como conclusión traemos una tabla referida a la evolución de los robots en el cine ${ }^{23}$ :

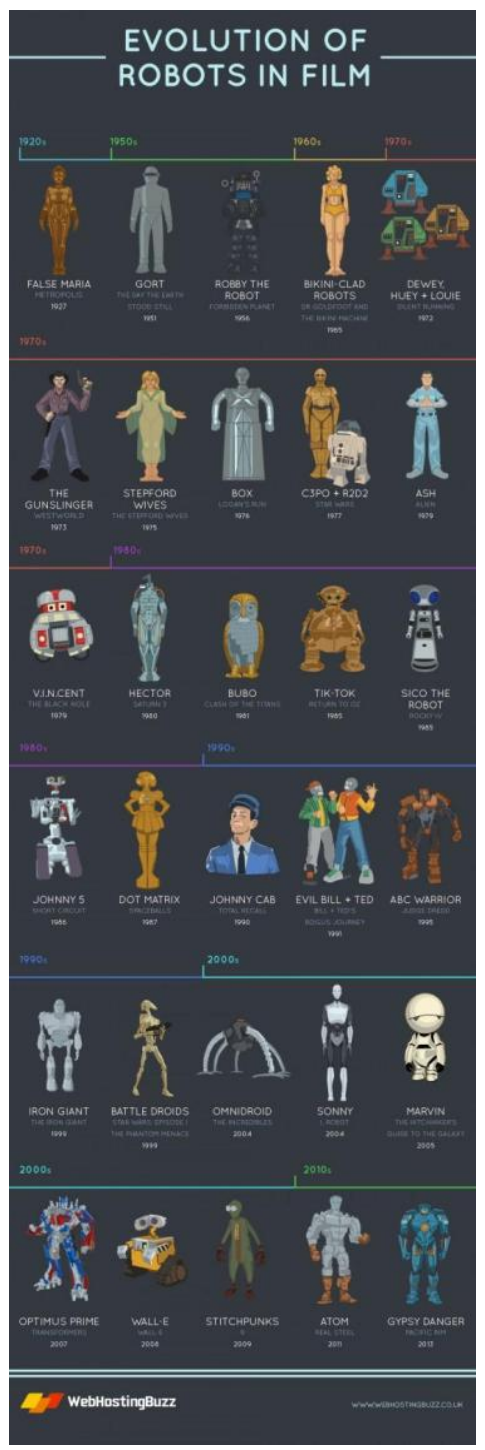

\footnotetext{
${ }^{23}$ https://robotsaldetalle.es/noticias/historia-de-los-robots-en-el-cine/
} 


\section{CONSECUENCIAS JURÍDICAS DE LA IMAGEN DEL ROBOT}

Tras el estudio de la evolución de la imagen del robot resulta posible enfrentar con mayor claridad los retos jurídicos que se afrontan. La imagen del robot oscila entre androides y máquinas alternativamente. Los robots similares al ser humano suscitan miedo e incertidumbre; por ello en ciertas décadas se huye de ellos, optando por la imagen del robot-máquina, más segura por su clara diferenciación respecto del ser humano.

La imagen del robot es fundamental, y podría resultar un apoyo o una desventaja en la interacción de robots con colectivos de personas necesitadas de una protección especial. En la regulación jurídica de la robótica parece necesario controlar la imagen del robot y su semejanza con el ser humano en los supuestos de interacción con sujetos necesitados de protección, que no distingan fácilmente realidad de ficción, por razón de edad o de limitaciones físicas o psíquicas temporales o permanentes.

\section{A MODO DE CONCLUSIÓN: ROBOT, IMAGEN Y DERECHO, MÁS CERCA DE LO QUE PUEDE PARECER}

Hay determinados aspectos muy interesantes y destacables, en el ámbito de lo jurídico, que nacen al hilo de la imagen, en especial de la imagen artística.

Se observa una oscilación, desde el punto de vista de la imagen y la ética, robots humanos, robots metálicos, robots para el bien, robots destructivos.

Con relación a la imagen, a la corporeidad del robot, resulta interesante cuestionarse si puede aplicarse a la robótica la idea de intimidad, o la idea de identidad. Se entiende por intimidad como el espacio de privacidad con relación al cuerpo a la información y todo lo que le rodea. La identidad personal es familiar, social.... sitúa al individuo como único "idéntico sólo a sí mismo a lo largo de su biografía con una personalidad específica" ${ }^{24}$. Parece que intimidad e identidad son solo calificativos del ser humano, no de la robótica; ello no impide preguntarse acerca de la privacidad de los sistemas y funcionamiento del robot, y de los datos en él recogidos. No intimidad, si privacidad, si bien, no del robot, sí de los seres humanos que los fabrican y utilizan. No obstante, ante las dudas que pudieran surgir, dejo ahí esta cuestión por si pudiera ser objeto de mayor desarrollo futuro.

En el ámbito de la imagen, en el siglo XIX, los cuerpos grotescos fuera de la norma eran exhibidos como desdichados, incompletos anormales, antinaturales, cercanos al monstruo ${ }^{25}$. En el momento actual, en el mundo occidental, el cuerpo humano es sometido a modificaciones de imagen en busca de la perfección o de un modelado específico según la estética y la moda dominantes. Con relación al robot es importante plantearse qué tipo de características se buscan en ese robot androide. ¿Se busca una máquina, o una similitud con el ser humano?; ¿cuál es la diferencia entre ambos?

La imagen del robot, especialmente interesante para el arte robótico, puede resultar aparentemente irrelevante en el mundo jurídico. Sin embargo, esto no es así, la transversalidad de la ciencia nos lleva a nuevos desarrollos. Así, podemos descubrir nuevas e interesantes

\footnotetext{
${ }^{24}$ PERA, C (2006): Pensar desde el cuerpo; ensayo sobre la corporeidad humana. Ed. Triacastela, Madrid, p. 33.

${ }^{25}$ PERA, C (2006): Pensar desde el cuerpo; ensayo sobre la corporeidad humana. Ed. Triacastela, Madrid, p. 36.
} 
facetas acerca de la imagen y sus consecuencias, en aras de la protección de la seguridad jurídica. La imagen del robot androide provoca temor, desconfianza, desconcierto... la imagen del robot humanoide o no metálico, sitúa a la figura en su justo lugar. La imagen es por ello importante también para el Derecho y la Ética, y puede tener una relevancia hasta ahora desconocida en los grupos de personas, y colectivos desfavorecidos o con limitaciones. En estos casos, parece que la semejanza del robot con el cuerpo humano puede suponer un hándicap, puede llevar a la confusión y desconcierto. Quizá debería evitarse la imagen del robot androide en la actuación con ciertos colectivos -menores de edad- para eliminar cualquier tipo de confusión y de abuso en el uso de los robots.

Es importante plantearse cómo debe ser la imagen y el cuerpo del robot para poder convivir con el ser humano, en función del contenido y uso del mismo. En el caso de los sujetos que requieren más protección hay que evitar la confusión, y tomar conciencia de que un exceso de relación emocional con una figura robótica cuasi humana puede causar daño y perjuicio a la persona.

Evidentemente, aunque el debate actual se centra en los códigos éticos de comportamiento, unos límites..., la corporeidad, la imagen y realidad física del robot también es un aspecto que debe ser estudiado e incidir en la ética y el derecho. Al menos desde aquí quiero dejar constancia de la necesidad de tomar conciencia, e incluso decisiones concretas con relación a la imagen y representación del robot.

Por otro lado, no es lo mismo hablar del robot en singular, qué en plural, como grupo o masa de robots, más aún cuando dicho grupo se orienta en una dirección concreta, tarea, fin... como vemos en la cinematografía robótica. Incluso aquí debe plantearse al servicio de quién actúa el robot, de qué intereses, o ideales, o personas... Pero también a imagen de quién se ha creado, de qué personas, intereses, imágenes. ¿Qué, o a quién, representa el robot?

Evidentemente, si el robot tiene un contenido determinado, a lo que responde su imagen, será más fácil su manejo; mientras que, si el contenido es difuso o cambiante, tanto en las posibilidades de lo que hace, como el material utilizado, y su imagen se presta a confusión... la situación se convierte en terreno abonado para que se puedan plantear problemas reales en la relación con el ser humano.

Por otro lado, al investigar sobre la corporeidad del robot, también debe plantearse cómo gestionar el espacio físico en que se desenvuelva el robot, tanto cuándo desempeñe su tarea, como cuando no lo haga. Cuando lo haga, con conocimiento y conciencia del ser humano, es más fácil -no así con personas con capacidad restringida como menores de edad-. También pueden surgir problemas cuando el ser humano no está presente o no controla la situación. A mí me surgen dudas... Por ejemplo, ¿se articulará un control 24 horas, presencial, o por control remoto, o un apagado temporal?

Por último, también interesa conocer qué hacer con el robot como realidad física cuando no funciona bien o cuando ya no tiene utilidad. ¿Debe ser objeto de reciclaje, debe ser abandonado, destruido, o amontonado junto con otros? 


\section{BIBLIOGRAFÍA}

- Anguiano, J.M. (2018): "Las personas electrónicas". Diario la Ley, núm. 14, sección Ciberderecho, 18 de enero de 2018. Disponible en:

http://diariolaley.laley.es/home/DT0000263132/20180118/Las-personas-electronicas, fecha de consulta enero de 2018.

- BARRIO ANDRÉS, M (2018): "Hacia una personalidad electrónica para los robots", Revista Derecho Privado. Núm. 2, marzo-abril 2018, pp. 89-107.

- DíAZ Alabart, S (2018): Robots y responsabilidad civil. Reus, Madrid 2018,

- GARcía PRIETO, J (2018): “QQué es un robot?” en Derecho de los robots, BARRIO ANDRÉS, M. (Dir.). La Ley 2018, pp. 25-61.

- CReco, C (2007): La muñeca el maniquí y el robot en el arte del siglo XX: perversa y utópica. Editorial Arada, Madrid 2007.

- Fernández, A; Barnechea Salo, E; Haro Sabater, J.R (2000): Historia del arte. Vicens-vives, Barcelona 2000.

- Gombrich, E.H (2002): Historia del arte. Ed. Debate, Madrid 2002.

- Iglesias García, R (2016): Arte y robótica. Casimiro, Madrid 2016.

- Lambea Rueda, A (2018): "Entorno digital, robótica y menores de edad". Revista de Derecho Civil, vol. V, núm. 4 (octubre-diciembre, 2018), Estudios, pp. 183-232.

- MeZa Rivas, M; EsPósito, C (2017): "Killer robots y sistemas de armas autónomos en el marco del derecho internacional. Implicaciones, desafíos y riesgos", Acta resumen y conclusiones de \#Robot Iuris 2017, 16 de noviembre de 2017, pp. 17-19.

- PAlmerini, E (2017): "Robótica y derecho: sugerencias, confluencias, evoluciones en el marco de una investigación europea". Revista de Derecho Privado, núm. 32, en-jun 2017, pp. 53 y ss.

- Pera, C (2006): Pensar desde el cuerpo; ensayo sobre la corporeidad humana. Editorial Triacastela, Madrid.

- SÁNChez-URÁn AZAÑA, y GRAU RUIZ, A: PONENCIA: "El impacto de la robótica, en especial, la robótica inclusiva en el trabajo: aspectos jurídico laborales y fiscales", en Congreso Internacional Technological innovation and the future of work: emerging aspects worldwide, Santiago de Compostela 4-5 abril 2018.

- $\quad$ https://hacedores.com/robotica-en-el-arte-y-arte-kinetico/

- https://www.nobbot.com/arte/robots-artistas-robotart/; https://www.xataka.com/robotica-eia/esta-obra-arte-fue-pintada-robot-ganadora-concurso-robotart-2018 .

- https://www.iberdrola.com/te-interesa/cultura/arte-computacional-robots-artistas

- https://robotsaldetalle.es/noticias/historia-de-los-robots-en-el-cine/

- https://www.filmaffinity.com/es/ (consultas 15 mayo 2019) 